\title{
COMPARATIVE STUDY BETWEEN LOW INCIDENCE X-RAY DIFFRACTION AND ELECTRON DIFFRACTION APPLIED TO TEXTURE DETERMINATION OF THIN FILMS OF $\mathrm{Cu} / \mathrm{NaCl}$
}

\author{
D. Schlatter, C. Baltzinger, A. Tizliouine, J. J. Heizmani, C. Burggraf* \\ Laboratoire de Metallurgie Physique \& Chimique, \\ METZ University - FRANCE \\ * I.C.P.M.S. - U.M. 380046 - C.N.R.S - U.L.P - E.H.I.C.S. et I. U.T. - U.L.P. \\ 67000 - STRASBOURG - FRANCE -
}

\section{INTRODUCTION :}

The determination of the texture of thin films has many applications in different industries (electronic, protection of surfaces, coating of glass,...).

We present a comparative study between the Bragg incidence or Low incidence XRay diffraction (1) and the electron diffraction.

We have choosen well known epitaxial coating : thin films of copper deposited on $\mathrm{NaCl}$ monocrystalline planes freshly cleaved.

We have studied the influence of the temperature of the substrate during the evaporation of copper and the texture of the evapored layer for different thicknesses of the film.

\section{SAMPLE PREPARATION :}

The thin films of copper have been obtained by evaporation under vacuum $\left(210^{-5}\right.$ torr).

The $\mathrm{NaCl}$ substrate freshly cleaved is fixed on to a copper plate heated with an electric coil, the temperature is measured by a thermocouple.

The thickness of the film has been measured in situ by transmission of light, through a glass plate, which is detected by a photoresistance cell ; the calibration of the cell has been done by measuring the thicknesses of the films by multiple beam interferometry.

The precision on the thickness is about $10 \%$.At the end of evaporation the sample is still maintened 15 minutes at the temperature of the substrate during evaporation in order to get a best organization of the copper at that temperature. 


\section{ELECTRON DIFFRACTION OBSERVATIONS}

The copper films have been detached from the substrate and observed by transmission of a $50 \mathrm{KeV}$ electron beam (HEED). The beam has a section of about

$1 \mathrm{~mm}^{2}$; the observed area is therefore comparable to the smallest area we used in XRD as we will see later.

At room temperature we obtain a polycrystalline film (600 $\AA$ ) without preferred orientation picture (1), at $350^{\circ}$ the copper film $(650 \AA)$ is well oriented : picture (2).

We notice in both cases the presence of $\mathrm{Cu}_{2} \mathrm{O}$ due to the superficial oxidation of the film after getting the film out of the evaporation plant.

\section{POLE FIGURE OBSERVATION}

We have used a multi-pole figures goniometer with a curved position sensitive detector (INEL CPS 120) equiped with a graphite monochromator.

The (111) $\mathrm{NaCl}$ lattice planes and the (111) copper lattice planes have been measured simultaneously in order to get the orientation relationships between the film and the substrate.

The pole figure of Nacl shows only the peaks given by a single crystal.

The film obtained at room temperature does not show any preferred orientation of the copper as it been also seen on HEED patterns. On the other hand, the oriented films give a pole figure revealing several orientations.

The raw one where of course the background has been substracted is presented on figure(1). As the films is not thick enough the diffracting volume changes according to the position of the sample with respect to the incident beam.(1)

The corrected pole figure taking into account the absorption of copper, the thickness of the film $t$ and its position $(\omega \varphi \psi)$ according to the $x$ ray beam is presented on figure (2). The intensity levels correspond after correction to an infinite thickness of the film, this thickness is reached for film thicker than a few micrometers.

One can notice a reinforcement of the boarder of the raw pole figure resulting from the fact that the length of the path of the $\mathrm{x}$ rays increases when the tilting angle increases to. These two kinds of pole figures are usefull ; the raw pole figure gives more information on the location of the orientations whereas the corrected pole figure must be used for quantitative analysis

\section{ORIENTATION OF THE COPPER}

The reference bounded to the $\mathrm{NaCl}$ are the (001) $\mathrm{NaCl}$ plane and the [110] $\mathrm{NaCl}$ row. The orientation of copper are given with respect to this reference. 
The different orientations found by using the pole figure are listed in table 1

Table I

\begin{tabular}{cccc}
\hline $\mathrm{N}^{\circ}$ & Copper & $\mathrm{NaCl}$ & Percentage \\
\hline 1 & $(001)[\overline{1} 10]$ & $(001)[\overline{1} 10]$ & $75 \%$ \\
2 & $(221)[\overline{1} 10]$ & $(001)[\overline{1} 10]$ & $9 \%$ \\
3 & $(111)[\overline{1} 10]$ & $(001)[\overline{1} 10]$ & $4 \%$ \\
4 & $(115)[\overline{5} \overline{5} 2]$ & $(001)[\overline{1} 10]$ & negligeable \\
5 & $(01010)[\overline{2} 011]$ & $(001)[\overline{1} 10]$ & $6 \%$ \\
6 & $(001)[\overrightarrow{3} 20]$ & $(001)[\overline{1} 10]$ & $6 \%$ \\
\hline
\end{tabular}

\section{QUANTITATIVE ANALYSIS OF THE POLE FIGURES}

On the corrected pole figure the intensities of peaks belonging to each orientation are measured and we obtain the percentage of the each kind of orientation as we can see on table I.

\section{COMPARISON BETWEEN HEED AND XRD.}

Let us see if we found the same orientations on the HEED patterns.

The first orientation is observed on picture (2) the intense spots correspond to this main orientation.

The second orientation is a (111) [112] twin of the first one generally observed in FFC lattices. Because of this twinning extra spots appear ; around the main spots as seen on picture (3)

The third orientation may be detected because of small reinforcement on the (111) ring ; we only can be sure of it because we got already the result from pole figure.

The fourth and the fifth orientations cannot be seen on such HEED diagrams.

For the last orientation the first indexation found by pole figure was $(001)$ [ $\overline{3} 50]$; HEED gives rather (001) [ $\overline{3} 20]$ in measuring a rotation of $11^{\circ}-12^{\circ}$ of the spots of the main orientation of copper. These new spots of course are less intense than the first ones

\section{LOW INCIDENCE X RAY DIFFRACTION}

We could'nt yet observe film thinner than $300 \AA$ with the Bragg Brentano incidence

With the low incidence method the apparent thickness of the film increases as the incidence angle decreases.

The copper film observed with this method was $250 \AA$ thick, we used an incidence angle of $8^{\circ}$ and a large beam. The scanning of the pole figure was $\Delta \psi=2^{\circ}$ and $\Delta \varphi=2,5^{\circ}$. 
We could'nt detect copper but owing to the use of the CPS detector, we could now detect the oxide $\mathrm{Cu}_{2}$. Such thin film of copper have probably been oxydized entirely within few days. The oxide orientation detected is mainly (110) $\mathrm{Cu}_{2} \mathrm{O} / /$ (001) $\mathrm{NaCl}$ with [ī10] $\mathrm{Cu}_{2} 0 / /[\overline{1} 10] \mathrm{NaCl}$ as we can see on pole figure (3)

This orientation is that one which was observed on $650 \AA$ copper film covered by $\mathrm{Cu}_{2}{ }^{0}$ _ Picture (2.)

Nevertheless there is a shift of $2^{\circ}$ to $3^{\circ}$ of the diffraction line this phenomenon has been frequently observed on thin films by different authors figure(4)

\section{CONCLUSION}

In this study we have shown that it was possible to give the orientations of films as thin as $300 \AA$ and to estimate the relativ importance of the different orientations. By using Bragg or low incidence texture goniometry. diffraction.

Nevertheless some complementary information can be obtained by Electron

\section{Bibliography:}

1. J.J. Heizmann, A. Vadon, D. Schlatter and J. Bessieres, Adv. in X-Ray Anal., 32 , 285 - 292 (1989).

2. Epitaxial Growth (part. A and B), (J.W. Mattews, Academic Press, New York 1975)

3 A.A. Chernov, Modern Crystallography 111 - Crystal Growth (Springer series in Solid-States Sciences, Berlin ,1984)

4 K.W.Andrews,..., Interpretation of Electron Diffraction Patterns, Part. 2.12 (Adam Hilger Ltd, London 1971) 
Picture 1:

polycrystalline copper film.

$\mathrm{Cu}+\mathrm{Cu} 2 \mathrm{O}$ rings
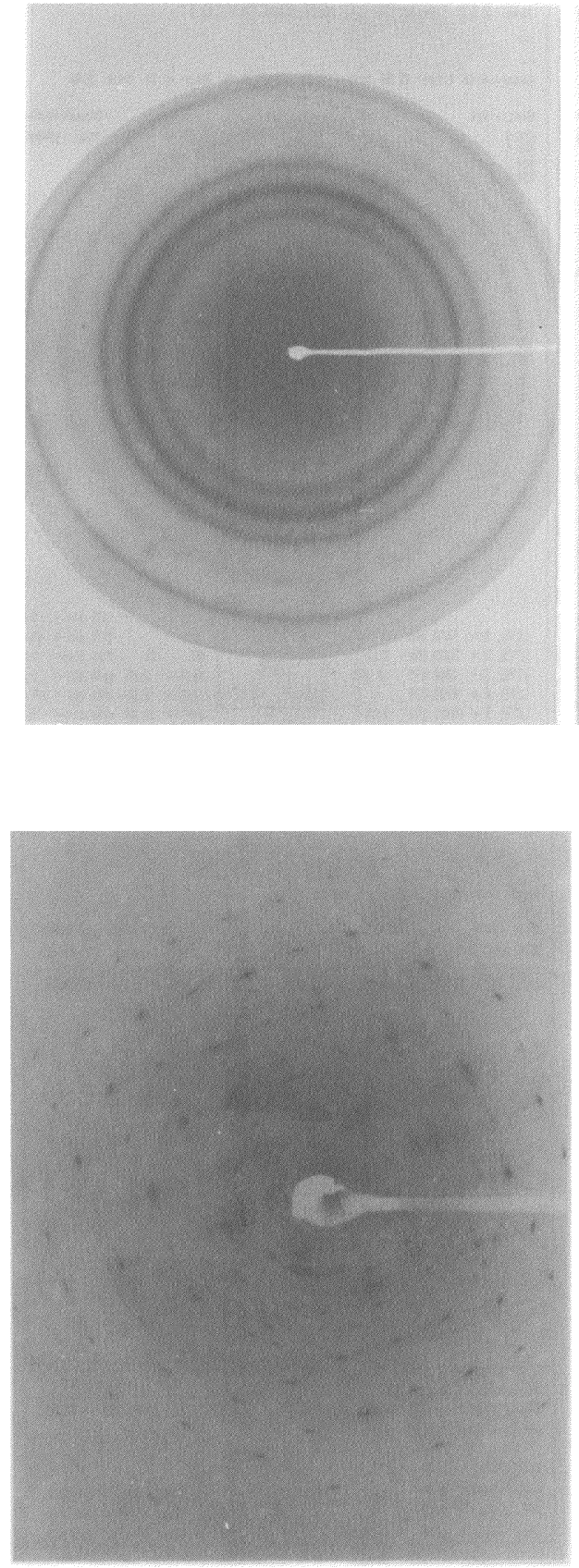

Picture 3 :

caracteristics extra spots of a twin around the 200 spots.

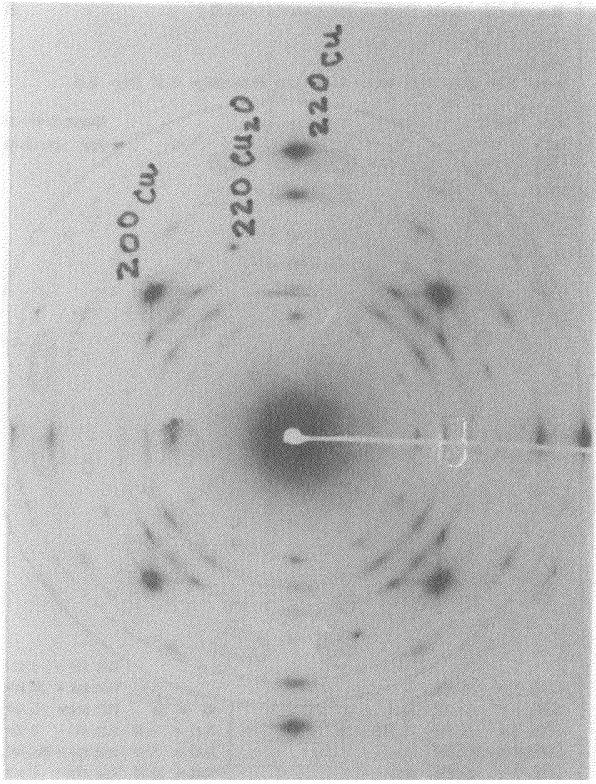

Picture 2 :

well oriented copper film

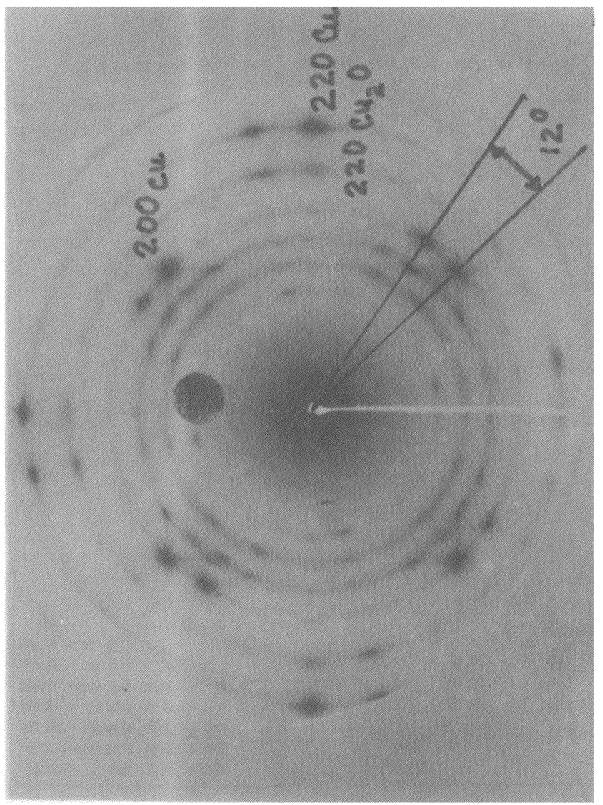

Picture 4 :

$12^{\circ}$ rotation of the main spots giving the (001)[320] orientation 
Figure 1:

raw (111) pole figure of $650 \AA$ copper film

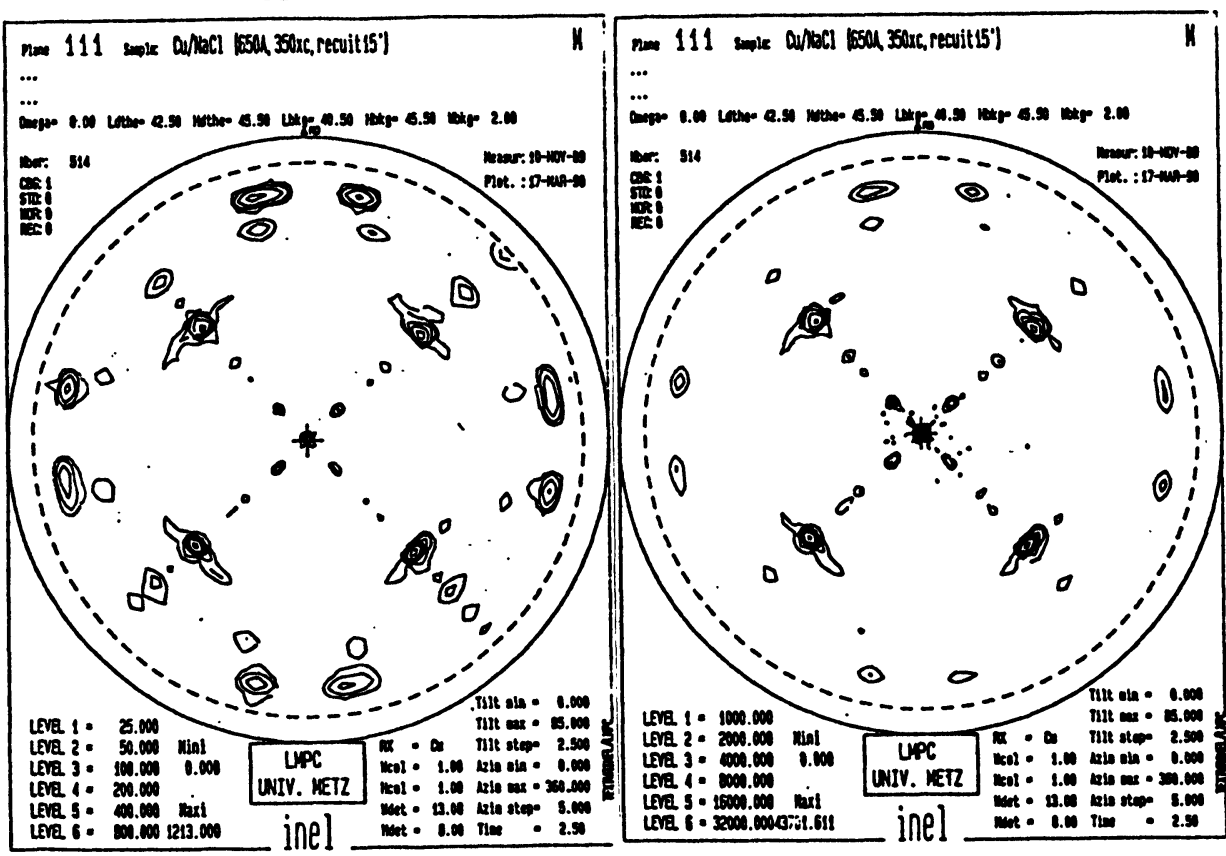

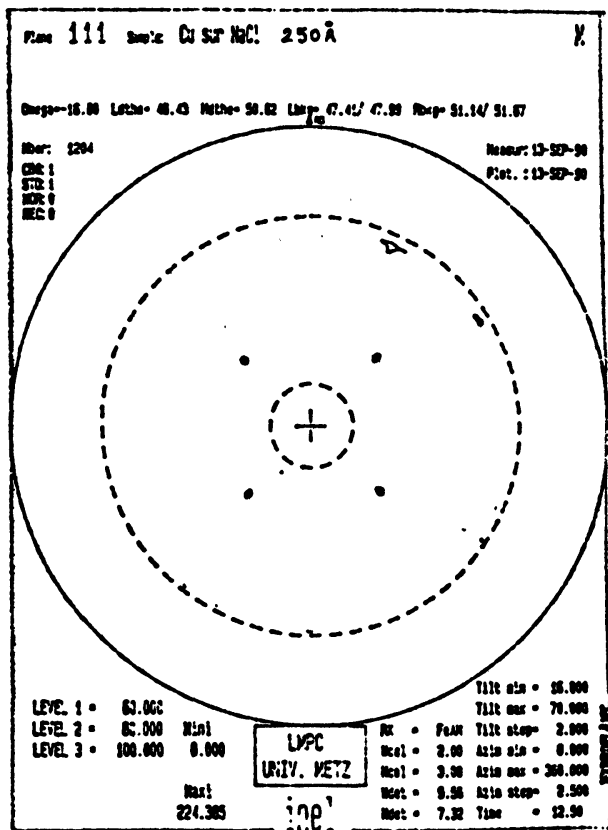

Figure 3:

Low incidence on a $250 \AA$ film (111) pole figure of $\mathrm{Cu} 2 \mathrm{O}$
Figure 2:

as fig. 1 with intensity corrections

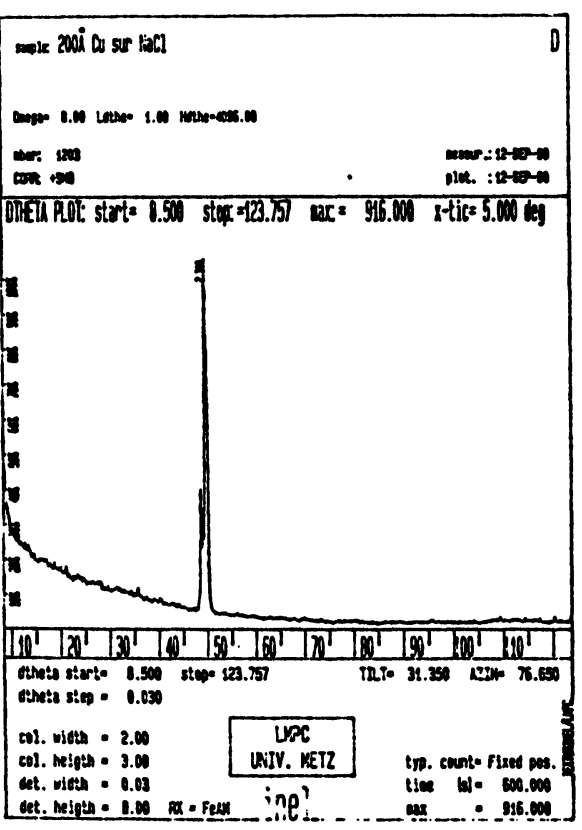

Figure 4:

$2 q$ spectrum taken at the maximum of the pole figure. 